\title{
Effects of a whole diet approach on metabolic flexibility, insulin sensitivity and postprandial glucose responses in overweight and obese adults - A randomized controlled trial
}

Citation for published version (APA):

Fechner, E., Bilet, L., Peters, H. P. F., Hiemstra, H., Jacobs, D. M., Op 't Eyndt, C., Kornips, E., Mensink, R. P., \& Schrauwen, P. (2020). Effects of a whole diet approach on metabolic flexibility, insulin sensitivity and postprandial glucose responses in overweight and obese adults - A randomized controlled trial. Clinical Nutrition, 39(9), 2734-2742. https://doi.org/10.1016/j.clnu.2019.12.010

Document status and date:

Published: 01/09/2020

DOI:

10.1016/j.clnu.2019.12.010

Document Version:

Publisher's PDF, also known as Version of record

\section{Document license:}

Taverne

Please check the document version of this publication:

- A submitted manuscript is the version of the article upon submission and before peer-review. There can be important differences between the submitted version and the official published version of record. People interested in the research are advised to contact the author for the final version of the publication, or visit the DOI to the publisher's website.

- The final author version and the galley proof are versions of the publication after peer review.

- The final published version features the final layout of the paper including the volume, issue and page numbers.

Link to publication

\footnotetext{
General rights rights.

- You may freely distribute the URL identifying the publication in the public portal. please follow below link for the End User Agreement:

www.umlib.nl/taverne-license

Take down policy

If you believe that this document breaches copyright please contact us at:

repository@maastrichtuniversity.nl

providing details and we will investigate your claim.
}

Copyright and moral rights for the publications made accessible in the public portal are retained by the authors and/or other copyright owners and it is a condition of accessing publications that users recognise and abide by the legal requirements associated with these

- Users may download and print one copy of any publication from the public portal for the purpose of private study or research.

- You may not further distribute the material or use it for any profit-making activity or commercial gain

If the publication is distributed under the terms of Article 25fa of the Dutch Copyright Act, indicated by the "Taverne" license above, 
Randomized Control Trials

\title{
Effects of a whole diet approach on metabolic flexibility, insulin sensitivity and postprandial glucose responses in overweight and obese adults - A randomized controlled trial
}

\author{
Eva Fechner ${ }^{\text {a, }}{ }^{*}$, Lena Bilet ${ }^{\text {a }}$, Harry P.F. Peters ${ }^{b}$, Harry Hiemstra ${ }^{b}$, Doris M. Jacobs ${ }^{b}$, \\ Cara Op 't Eyndt a, Esther Kornips a, Ronald P. Mensink a , Patrick Schrauwen ${ }^{a}$ \\ ${ }^{a}$ Department of Nutrition and Movement Sciences, NUTRIM School of Nutrition and Translational Research in Metabolism, Maastricht University Medical \\ Center+, Maastricht, the Netherlands \\ ${ }^{\mathrm{b}}$ Unilever Food Innovation Center, Wageningen, the Netherlands
}

\section{A R T I C L E I N F O}

\section{Article history:}

Received 29 July 2019

Accepted 6 December 2019

\section{Keywords:}

Dietary intervention

Insulin resistance

Hyperinsulinemic euglycemic clamp

Mixed meal challenge

Postprandial metabolism

Obesity

\begin{abstract}
S U M M A R Y
Background \& aims: Metabolic flexibility is the ability to adapt fuel oxidation to fuel availability. Metabolic inflexibility has been associated with obesity, the metabolic syndrome and insulin resistance, and can be improved by exercise or weight loss. Dietary changes can modulate metabolic flexibility; however, the effect of a whole diet approach on metabolic flexibility has never been studied. Therefore, our objective was to assess the effect of a healthy diet (HD), as compared to a typical Western diet (WD), on several fasting and postprandial markers of metabolic flexibility and insulin sensitivity.

Methods: In this parallel randomized trial, overweight or obese men and women (50-70 years; BMI 25 $-35 \mathrm{~kg} / \mathrm{m}^{2}$ ) consumed a healthy diet (HD; high in fruits and vegetables, pulses, fibers, nuts, fatty fish, and low in high-glycemic carbohydrates; $n=19$ ) or a typical Western diet (WD; $n=21$ ) for six weeks, following a two-week run-in period. The change in respiratory quotient upon insulin stimulation $(\Delta R Q)$, and insulin sensitivity, expressed as the M-value, were both determined with a hyperinsulinemic euglycemic clamp. Additionally, other fasting and postprandial markers of metabolic flexibility were assessed during a 5-h high-fat high-glycemic mixed meal challenge.

Results: $\Delta \mathrm{RQ}(\mathrm{p}=0.730)$ and insulin sensitivity $(\mathrm{p}=0.802)$ were not significantly affected by diet. Postprandial RQ did also not show significant differences $(\mathrm{p}=0.610)$, whereas postprandial glucose excursions were significantly higher in the HD group at T30 $(\mathrm{p}=0.014)$ and T45 $(\mathrm{p}=0.026)$ after mixed meal ingestion $(p=0.037)$. Fasting glucose $(p=0.530)$ and $\operatorname{HbA1c}(p=0.124)$ remained unchanged, whereas decreases in fasting insulin $(p=0.038)$ and the HOMA-IR $(p=0.050)$ were significantly more pronounced with the HD.

Conclusion: A healthy diet for six weeks, without further life-style changes, did not improve metabolic flexibility and whole-body insulin sensitivity, when compared to a Western-style diet. It remains to be determined whether the short time increase in postprandial glucose is physiologically relevant or detrimental to metabolic health.

This trial was registered at clinicaltrials.gov as NCT02519127.
\end{abstract}

๑) 2019 Elsevier Ltd and European Society for Clinical Nutrition and Metabolism. All rights reserved.

\section{Introduction}

Nutrition research aims at improving health and preventing diseases. Implying more than merely the absence of disease or

\footnotetext{
Abbreviations: HD, healthy diet; WD, Western diet; RQ, respiratory quotient; $\triangle \mathrm{RQ}$, metabolic flexibility; GIR, glucose infusion rate; FFA, free fatty acids; CONGA, continuous overall net glycemic action; $\mathrm{CHO}$, carbohydrate.

* Corresponding author. Maastricht University Medical Center+, P.O. BOX 616, 6200, MD, Maastricht, the Netherlands.

E-mail addresses: e.fechner@maastrichtuniversity.nl (E. Fechner), p.schrauwen@ maastrichtuniversity.nl (P. Schrauwen).
}

infirmity, health has been defined as the ability to cope with daily challenges [1], also called phenotypic flexibility. This concept is also established in nutrition research as metabolic flexibility, which is the capacity of the body to match fuel oxidation to fuel availability, reflecting the ability to switch between the main energy substrates carbohydrates and fats [2,3]. Typically, metabolic flexibility is expressed as the change in respiratory quotient $(\Delta R Q)$ from fasting to insulin-stimulated or postprandial conditions and can be measured by indirect calorimetry $[3,4]$. Our interest in metabolic flexibility derives from the hypothesis that dynamic physiological 
responses to a challenge are more indicative of health than the more common baseline measurements of the homeostatic state only [1].

Indeed, metabolic flexibility has been shown to play an important role in metabolic health, and impaired metabolic flexibility has been associated with obesity, the metabolic syndrome, insulin resistance and diabetes [5-8]. The fundamental determinants of a reduced metabolic flexibility are a decreased fat oxidation in the fasting state, as reflected by a higher fasting RQ and/or a decreased insulin-stimulated glucose oxidation, and is often accompanied by an impaired suppression of free fatty acid release (lipolysis) in response to insulin [9]. Metabolic flexibility can be improved by lifestyle changes such as exercise, caloric restriction and weight loss, in combination with healthier eating patterns [10,11]. Malin et al. [12] found a positive effect on metabolic flexibility by replacing refined grain with whole grain products for eight weeks with a comparable macronutrient intake in both intervention groups. However, whether a whole diet approach, without further life style changes, can improve metabolic flexibility, still needs to be determined $[13,14]$. Therefore, we composed a healthy diet (HD), comprising nutrients which have been shown to improve glycemic control and/or to reduce metabolic syndrome risk factors. The HD was high in fruits and vegetables [15], pulses [16], legumes [17], fibers [18], nuts [19], fatty fish and polyunsaturated fatty acids [20], and low in high-glycemic carbohydrates [21] and saturated fatty acids [22]. We assessed the effect of the HD, as compared to a more common Western diet (WD), on the $\triangle \mathrm{RQ}$ upon insulin stimulation, and on insulin sensitivity, determined with a hyperinsulinemic euglycemic clamp. Focusing on the dynamic physiological responses, other markers of metabolic flexibility were measured not only in the fasting state, but also postprandially with a 5-h mixed meal challenge. Based on the phenotypic flexibility principle, we hypothesized that the HD, compared to the WD, would improve $\Delta \mathrm{RQ}$ insulin sensitivity, and the other fasting and postprandial markers of metabolic flexibility.

\section{Methods}

\subsection{Participants}

In total, 64 participants were recruited via advertisement in local newspapers in and around Maastricht and assessed for eligibility. Forty-five participants were randomly assigned to one of the diet groups and 40 middle-aged (50-70 years) healthy, but overweight or obese (body mass index (BMI) $25-35 \mathrm{~kg} / \mathrm{m}^{2}$ ) men (waist circumference $>94 \mathrm{~cm}, \mathrm{n}=19$ ) and women (waist circumference $>80 \mathrm{~cm}, \mathrm{n}=21$ ) completed the study and were included in the analyses. Participants were considered to be healthy when they did not have any medical condition which might have affected the study measurements, i.e. metabolic disorders, including type 1 and type 2 diabetes, gastrointestinal dysfunction, gastrointestinal surgery or inflammatory diseases. Participants with a fasting plasma glucose of $>6.9 \mathrm{mmol} / \mathrm{l}$ were also excluded. Further exclusion criteria were smoking, shift work, excessive alcohol consumption (>7 consumptions per week), medically prescribed diets, slimming diets, being vegetarian, doing more than $2.5 \mathrm{~h}$ of moderate to vigorous physical activity per week, reported weight loss or gain of $>10 \%$ in the past 6 months, and medication which could have interfered with the study measurements. All participants gave their written informed consent prior to the start of the study. The study was conducted according to the guidelines stated in the Declaration of Helsinki and the protocol was approved by the medical ethical committee of Maastricht University Medical Centre+ (MUMC + ) and registered at www.clinicaltrials.gov as NCT02519127.

\subsection{Study design}

This study was a parallel-designed randomized trial with two intervention groups. All participants received the WD during a twoweek run-in period to minimize nutritional differences at the start of the intervention, and to stay close to the general Dutch eating habits [23]. After the run-in period, all participants underwent two different test days in randomized order, separated by two days in which the WD was still followed. On one of the test days, a hyperinsulinemic euglycemic clamp was carried out to assess $\Delta \mathrm{RQ}$ and insulin sensitivity. On the other test day, a 5-h mixed meal challenge was performed to assess other fasting and postprandial markers of metabolic flexibility. Thereafter, participants were allocated to either the WD or the HD for six weeks. Randomization was based on a computer-generated stratified (men, women and couples) randomization scheme. Participants were asked to visit the test facility weekly to discuss the diets and meal plans with a research dietician, to have their weight and waist circumference monitored, and to receive the required food products. In addition to the weekly appointments, participants were asked to monitor their daily food intake and to fill in a detailed 3-day food dairy during the run-in period and in the final week of the intervention. At the end of the study, the mixed meal challenge and the clamp were repeated in the same order as during the run-in period, separated by two days in which participants followed the allocated diet. A schematic overview of the study design is shown in Fig. 1.

\subsection{Diets}

For each participant, energy intake was estimated using the Harris-Benedict formula adjusted with a physical activity level of 1.40 , which reflects the activity within a sedentary or light activity lifestyle $[24,25]$. The outcome was translated into dietary guidelines for each participant. The guidelines included the types and amounts of foods they were allowed to consume, example menus and recipes. For both the WD and the HD, a standard set of food products was provided on a weekly basis, providing approximately $50 \%$ of the total energy intake and taking individual food preferences into account. The rest of the products had to be bought by the

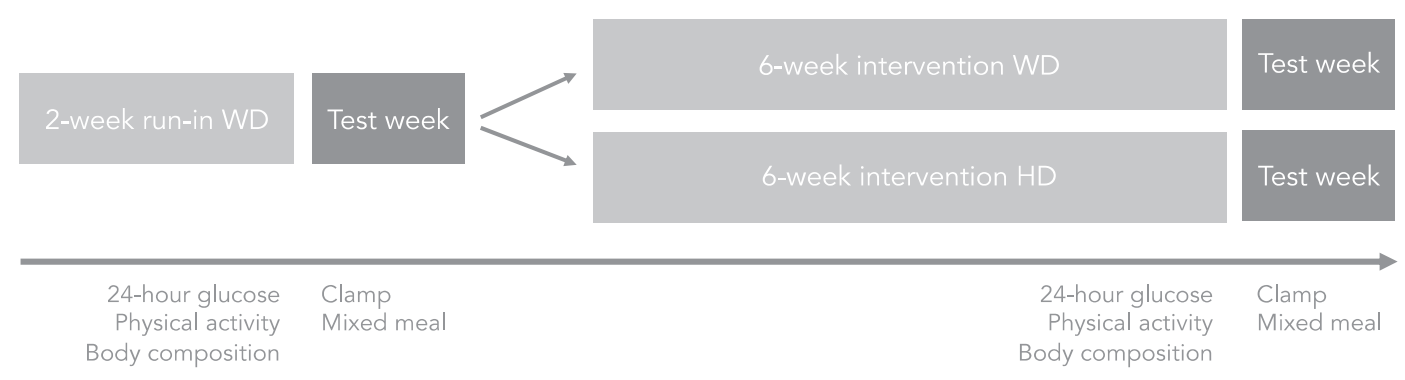

Fig. 1. Study design and measurements. 
participants according to the dietary guidelines. Alcohol consumption was restricted to one beverage per day. Participants were instructed to adhere to their recommended energy intake in order to maintain body weight throughout the study. In case of weight loss or gain, the research dietician provided additional counseling and energy intake was adjusted if necessary. Main differences between the two diets were the amount and type of carbohydrates and the fatty acid composition. The HD contained more fruits and vegetables, especially fruits and vegetables rich in polyphenols, legumes, fibers, nuts, whole grain products, (fatty) fish, polyunsaturated fatty acids and protein, and less sodium, mono- and disaccharides, high-glycemic carbohydrates and saturated fatty acids than the WD. The target nutrient amounts for both diets are shown in Supplementary Table 1.

\subsection{Test days and measurements}

Participants were asked to refrain from physical activity and from the consumption of alcoholic drinks two days prior to both test days. On the evening before both test days, participants were instructed to consume a standardized dinner and to abstain from any other foods and drinks, except for water, after $10 \mathrm{PM}$. The standardized dinner was the same for both intervention groups at the end of the run-in period and consisted of a commercially available ready-to-eat meal and dessert (761 kcal, $106 \mathrm{~g}$ carbohydrates, $25 \mathrm{~g}$ fat and $28 \mathrm{~g}$ protein). The meal differed for the HD at the end of the intervention period ( $682 \mathrm{kcal}, 71 \mathrm{~g}$ carbohydrates, $26 \mathrm{~g}$ fat and $41 \mathrm{~g}$ protein), reflecting the targeted differences in macronutrient composition between the diets.

\subsubsection{Hyperinsulinemic-euglycemic clamp}

After an overnight fast, participants came to the test facility at the University in Maastricht, where their weight and waist circumference were measured. To measure peripheral insulin sensitivity, a 2.5-h 1-step hyperinsulinemic-euglycemic clamp was performed as described previously [26]. Before starting the clamp, two cannulas were inserted, one for withdrawing venous blood and one for simultaneous infusion of insulin $\left(40 \mathrm{mU} / \mathrm{m}^{2} / \mathrm{min}\right)$ and glucose $(20 \%)$ during the clamp. Throughout the whole clamp, a small amount of blood was withdrawn every 5-10 min to continuously determine the plasma glucose concentrations. The glucose infusion rate (GIR) was adjusted to maintain a stable plasma glucose level of $5 \mathrm{mmol} / \mathrm{l}$ and to determine insulin sensitivity based on the calculated M-value $(\mathrm{mg} / \mathrm{kg} / \mathrm{min})$. Fasting and insulinstimulated indirect calorimetry was performed for $30 \mathrm{~min}$ each with an automated ventilated hood system (Omnical, Maastricht Instruments, Maastricht University, the Netherlands) to measure the respiratory quotient [27] in the fasting and insulin-stimulated state. $\triangle \mathrm{RQ}$ was calculated by subtracting the mean insulinstimulated RQ of 30 min (T120-150) by the mean fasting RQ of $30 \mathrm{~min}(\mathrm{~T}-30-0)$. Carbohydrate and lipid oxidation were calculated as described previously [28]. Additional blood sampling was done to measure fasting (T0) and insulin-stimulated (T30, T60, T90, T120 and T150) FFA concentrations.

\subsubsection{Mixed meal challenge}

After an overnight fast, participants came to the test facility at the University in Maastricht, and a cannula was inserted in the antecubital vein for collecting a fasting blood sample. The fasting $\mathrm{RQ}(\mathrm{T}-30-0)$ was measured as before the clamp. After this baseline measurement, participants were asked to consume a test meal in the form of a shake, resembling the composition of a mixed meal (Supplementary Table 2), within $10 \mathrm{~min}$. As previously described, an optimal nutritional challenge contains predominantly fat (50-60 E\%), but also high-glycemic carbohydrates and protein to activate more metabolic pathways with only one meal for assessing a broader range of metabolic markers [29]. The composition of the shake was the same for all participants, regardless of their randomization. After consuming the shake, participants were asked not to eat or drink, except for water, for $5 \mathrm{~h}$. Postprandial blood samples were taken at T15, T30, T45, T60, T90, T120, T180, T240 and T300 min after shake consumption. Indirect calorimetry was performed at five different time intervals after shake consumption, namely T30-60, T90-120, T150-180 and T240-300 min to monitor changes in the postprandial RQ.

\subsubsection{Twenty-four-hour glucose monitoring}

At the end of the run-in and the intervention period, glucose levels were monitored with a continuous glucose monitor iPRO ${ }^{\mathrm{TM}} 2$ (Medtronic, Maastricht, The Netherland) for $24 \mathrm{~h}$ as described earlier [30]. A needle-shaped sensor was inserted subcutaneously beside the navel to measure glucose concentrations in the interstitial fluid every $5 \mathrm{~min}$. The measured concentrations were corrected for blood glucose levels, which were measured by the participants at home four times per day using a hand glucose meter (ACCU-CHEK, Roche Diabetes Care GmbH, Mannheim, Germany). Based on the 24-h glucose measurement, mean 24-h glucose levels, time of hyperglycemia, and intra-day glycemic variability were calculated. Hyperglycemia was defined as glucose levels increasing more than $1.5 \mathrm{mmol} / \mathrm{l}$ above the mean 24 -h glucose levels. In order to assess intra-day glycemic variability, the continuous overall net glycemic action (CONGA) method was used as described earlier [31].

\subsubsection{Physical activity monitoring}

At the end of the run-in and intervention period, subjects were also asked to wear an activity monitor (activPAL, PAL Technologies Ltd, Glasgow, UK) for five consecutive days, including two weekend days. The activPAL is a small flat device which is attached directly to the skin on the anterior thigh, and thus can be worn under regular clothing. The activPAL monitored physical activity based on the average number of steps taken per day [32]. To determine differences in body composition, the deuterium dilution method was used before and after the intervention [33].

\subsection{Blood sampling and analysis}

Blood was sampled in serum, NaF- and EDTA-containing vacutainer tubes (Beckton Dickinson, Breda, the Netherlands). The serum tubes were left for clotting for at least $30 \mathrm{~min}$ after sampling and were then centrifuged at $3000 \mathrm{rpm}$ at $20^{\circ} \mathrm{C}$ for $10 \mathrm{~min}$. The NaF and EDTA tubes were cooled on ice directly after sampling and were centrifuged at $3000 \mathrm{rpm}$ for $10 \mathrm{~min}$ at $4{ }^{\circ} \mathrm{C}$ within $30 \mathrm{~min}$ after sampling. Following centrifugation, the obtained serum and plasma samples were directly frozen in liquid nitrogen and subsequently stored at $-80^{\circ} \mathrm{C}$ until later analysis.

All samples from the same participant were analyzed within the same analytical run at the end of the study. From the mixed meal challenge and the clamp, fasting glucose was measured in NaFplasma (Horiba ABX, Montpellier, France) and fasting insulin was determined with a human insulin-specific radioimmunoassay (RIA) kit (Linco Research, Missouri, USA). Postprandial glucose and insulin were only sampled during the mixed meal challenge and measured in the same way as the fasting plasma samples. Fasting and insulin-stimulated/postprandial plasma free fatty acids (WAKO Chemicals, Neuss, Germany) were measured from both test days. Serum concentrations of related metabolites and all fasting amino acids were determined by nuclear magnetic resonance as described by Mihaleva et al. [34]. 


\subsection{Statistical analysis}

The power calculation was based on the change in $\Delta R Q$ during a hyperinsulinemic euglycemic clamp as primary outcome measure. Before the start of the study, it was calculated that 16 participants were needed to reach a power of $80 \%$ to detect a true difference of 0.04 in $\Delta \mathrm{RQ}$ [35]. For these calculations, a two-sided alpha of 0.05 and a standard deviation of 0.04 were used. With an expected dropout rate of 30\%, 21 participants per group were recruited. Due to the randomization scheme, which allowed us to allocate couples to the same diet group, we ended up with 21 participants in the WD and 19 participants in the HD group.

Statistical analyses were performed using the statistical software package SPSS 24.0 for Mac OS X (SPSS Inc., Chicago, IL, USA). Results are presented as means and standard errors of the means (SEMs). For the primary outcome parameter, the differences between the HD and WD group in the diet-induced change in $\triangle R Q$ before and after the intervention were assessed by a one-way ANCOVA with baseline values of the outcome variable as covariate. The same method was used for the secondary outcome parameters, i.e. insulin sensitivity and all fasting markers of metabolic flexibility.

A repeated measures linear mixed model was used to examine the effect of diet on the overall changes in the postprandial plasma/ serum marker profiles measured during the mixed meal challenge before and after the diet intervention: (post WD-pre WD) vs (post HD-Pre HD). In all models, diet was added as a categorical variable with 4 levels (pre WD, post WD, pre HD and post HD). Also, the time point - or the time interval for the RQ measurement - relative to the start of the mixed meal was treated as a categorical variable. All models contained diet, time and the diet*time interaction as fixed factors. Subject code was added as random factor. Sex, BMI and age could enter the model as covariates. To correct for differences at baseline, the response at baseline (T0) could enter the model as continuous variable. Changes at specific time points were extracted from the diet*time-group interaction.

The best fitting model for each response variable was selected based on the Bayesian Information Criterion (BIC) as a goodness of fit criterion. The model with the smallest BIC was chosen after assessing all possible predictor combinations (BMI, sex and age). The correlations between the observations within a series of measurement over time in the same subject were considered by the model. The same was true for the correlated observations before and after the same diet.

For fasting and postprandial testing, differences were considered statistically significant at a two-sided significance level of $\mathrm{p}<0.05$. The estimated differences and the $95 \%$ confidence intervals of these differences are reported.

\section{Results}

\subsection{Baseline characteristics and compliance}

The participant's baseline characteristics are shown in Table 1. After the screening visit, 19 participants were excluded, and 45 participants were eligible for participation. During the run-in period, 5 participants discontinued the study either due to difficulties with diet compliance ( 2 males and 1 female) or for nonstudy related reasons ( 2 males). Based on the study conduct review by the study team, all 40 participants were considered to be compliant and therefore included in the analysis (Supplemental Fig. 1). Compliance criteria were adherence to the medication restrictions stated in the inclusion criteria, adherence to the diets as judged by the study dietician, and body weight maintenance within a range of $\pm 5 \%$ during the six-weeks intervention period. Mean
Table 1

Subjects' baseline characteristics before the run-in period. ${ }^{a}$

\begin{tabular}{lll}
\hline & WD $(\mathrm{n}=21)$ & HD $(\mathrm{n}=19)$ \\
\hline Age $($ years $)$ & $60.6 \pm 1.50$ & $62.2 \pm 1.28$ \\
Sex $(\mathrm{m} / \mathrm{f})$ & $10 / 11$ & $9 / 10$ \\
Height $(\mathrm{m})$ & $1.71 \pm 0.02$ & $1.71 \pm 0.02$ \\
Weight $(\mathrm{kg})$ & $86.2 \pm 2.47$ & $85.4 \pm 1.95$ \\
BMI $\left(\mathrm{kg} / \mathrm{m}^{2}\right)$ & $29.5 \pm 0.60$ & $29.2 \pm 0.57$ \\
Waist circumference $(\mathrm{cm})$ & $104 \pm 2.15$ & $102 \pm 2.33$ \\
Fasting glucose $(\mathrm{mmol} / \mathrm{l})$ & $5.85 \pm 0.16$ & $5.51 \pm 0.09$ \\
Fasting FFA $(\mu \mathrm{mol} / \mathrm{l})$ & $342 \pm 142$ & $383 \pm 174$ \\
\hline
\end{tabular}

${ }^{\text {a }}$ Data is expressed as means \pm SEM. FFA: free fatty acids; HD: healthy diet; WD: Western diet.

weight changes were $-1.19 \pm 0.30 \mathrm{~kg}(-1.5 \%)$ with the $\mathrm{HD}$ and $+0.05 \pm 0.16 \mathrm{~kg}(+0.1 \%)$ in the WD group, without differences in fat mass $(p=0.247)$ and fat free mass $(p=0.157)$. Waist circumference decreased by $-0.36 \pm 0.22 \mathrm{~cm}(-0.4 \%)$ in the HD group and by $-0.17 \pm 0.47 \mathrm{~cm}(-0.1 \%)$ in the WD group $(\mathrm{p}=0.692)$. Changes in weight were significantly different between the diet groups $(p=0.001)$, but individual differences in weight $(-3.2-1.9 \mathrm{~kg})$ stayed within an acceptable range of $<5 \%$. Physical activity, based on the number of daily steps, was not significantly different between the diets (HD $+608 \pm 887$ vs WD $+107 \pm 450$ steps, $\mathrm{p}=0.427$ ). In addition to the anthropometric compliance markers, urinary sodium and potassium concentrations were measured. Reflecting the lower sodium content of the HD, urinary sodium significantly decreased in this group, compared to the WD $(\mathrm{HD}-28.2 \pm 6.79 \mathrm{mmol} / \mathrm{l}$ vs $\mathrm{WD}+9.22 \pm 7.30 \mathrm{mmol} / \mathrm{l}, \mathrm{p}=0.001)$. Changes in urinary potassium concentrations were not significant $(\mathrm{HD}+5.36 \pm 6.34 \mathrm{mmol} / \mathrm{l}$ vs $\mathrm{WD}+3.93 \pm 9.25 \mathrm{mmol} / \mathrm{l}, \mathrm{p}=0.300)$.

\subsection{Nutrient intake}

During the run-in period, no significant differences in energy and nutrient intakes between the WD and HD groups were observed. Energy intake and total fat intake remained comparable between the groups during the whole intervention period. Dietrelated changes in nutrient intakes were as intended and are shown in Table 2.

\subsection{Fasting $R Q$ and metabolic flexibility ( $\Delta R Q)$ during the clamp}

When compared to the $\mathrm{WD}$, fasting $\mathrm{RQ}$ as measured before the start of the clamp, was not significantly affected in the HD group $(\mathrm{p}=0.472$, Table 3$)$. Consistently, no significant diet effect was found in fasting lipid ( $\mathrm{p}=0.661)$ and carbohydrate $(\mathrm{p}=0.311)$ oxidation (Table 3 ). Metabolic flexibility $(\Delta R Q)$ was not significantly different between the diet groups ( $\mathrm{p}=0.730$, Table 3$)$. In agreement, the insulin-induced stimulation of carbohydrate oxidation ( $p=0.493)$, as well as the insulin-induced inhibition of fat oxidation ( $\mathrm{p}=0.848$ ) were not significantly different between the two groups (Table 3 ).

\subsection{Insulin sensitivity as determined by the clamp}

Insulin sensitivity, as expressed as the M-value, did not significantly differ between the two diet groups $(p=0.802)$. Fasting plasma FFA remained comparable between diets $(p=0.906$, Table 3), and the insulin-induced suppression of FFA, reflecting adipose tissue insulin sensitivity, was not affected by the intervention ( $p=0.322$, Fig. $2 A, B)$. 
Table 2

Daily nutrient intake with the healthy diet and the Western diet at the end of the run-in period and at the end of the intervention. ${ }^{a}$

\begin{tabular}{|c|c|c|c|c|c|c|c|}
\hline & \multicolumn{2}{|l|}{$\mathrm{WD}(\mathrm{n}=21)$} & \multicolumn{2}{|l|}{$\mathrm{HD}(\mathrm{n}=19)$} & \multicolumn{3}{|c|}{ TREATMENT EFFECT $^{\mathrm{b}}$} \\
\hline & Run-in & Intervention & Run-in & Intervention & Mean differences & $95 \% \mathrm{CI}$ & p-value \\
\hline Energy (kcal) & $2195 \pm 85.6$ & $2165 \pm 78.4$ & $2164 \pm 82.1$ & $2190 \pm 99.5$ & $42.9 \pm 107$ & $-174-259$ & 0.690 \\
\hline Total carbohydrates (E\%) & $49.3 \pm 0.64$ & $47.8 \pm 0.73$ & $49.0 \pm 0.76$ & $39.7 \pm 0.77$ & $-8.00 \pm 1.06$ & $-10.2--5.84$ & $<0.001$ \\
\hline Mono- and disaccharides (E\%) & $23.1 \pm 0.61$ & $22.1 \pm 0.64$ & $22.1 \pm 0.46$ & $14.7 \pm 0.79$ & $-7.23 \pm 1.03$ & $-9.31--5.14$ & $<0.001$ \\
\hline Polysaccharides (E\%) & $26.0 \pm 0.46$ & $25.6 \pm 0.46$ & $26.7 \pm 0.48$ & $24.1 \pm 0.56$ & $-1.64 \pm 0.72$ & $-3.09--0.18$ & 0.029 \\
\hline Fiber $(\mathrm{g})$ & $20.2 \pm 0.70$ & $18.4 \pm 0.84$ & $19.7 \pm 0.65$ & $43.0 \pm 2.18$ & $25.9 \pm 2.15$ & $21.5-30.3$ & $<0.001$ \\
\hline Total fat (E\%) & $34.4 \pm 0.43$ & $35.1 \pm 0.71$ & $34.9 \pm 0.82$ & $35.7 \pm 0.84$ & $0.79 \pm 1.09$ & $-1.42-3.00$ & 0.473 \\
\hline Saturated fatty acids (E\%) & $15.5 \pm 0.29$ & $15.8 \pm 0.49$ & $15.7 \pm 0.38$ & $7.88 \pm 0.24$ & $-7.98 \pm 0.56$ & $-9.12--6.84$ & $<0.001$ \\
\hline Monounsaturated fatty acids (E\%) & $11.3 \pm 0.27$ & $11.8 \pm 0.28$ & $11.6 \pm 0.35$ & $14.3 \pm 0.62$ & $2.57 \pm 0.67$ & $1.21-3.92$ & $<0.001$ \\
\hline Polyunsaturated fatty acids (E\%) & $4.64 \pm 0.14$ & $4.51 \pm 0.16$ & $4.54 \pm 0.23$ & $10.0 \pm 0.21$ & $5.51 \pm 0.26$ & $4.98-6.05$ & $<0.001$ \\
\hline Alpha-linolenic acid (mg) & $917 \pm 39.2$ & $983 \pm 67.8$ & $908 \pm 36.4$ & $3416 \pm 172$ & $2438 \pm 182$ & $2067-2808$ & $<0.001$ \\
\hline Eicosapentaenoic acid (mg) & $24.2 \pm 1.76$ & $27.4 \pm 2.74$ & $23.9 \pm 2.31$ & $286 \pm 41.9$ & $259 \pm 41.2$ & $176-343$ & $<0.001$ \\
\hline Docosahexaenoic acid (mg) & $17.9 \pm 2.92$ & $25.8 \pm 4.48$ & $16.7 \pm 2.56$ & $418 \pm 73.6$ & $390 \pm 72.3$ & $243-537$ & $<0.001$ \\
\hline Linoleic acid $(\mathrm{g})$ & $9.31 \pm 0.52$ & $8.81 \pm 0.49$ & $8.82 \pm 0.51$ & $20.3 \pm 1.16$ & $11.7 \pm 1.24$ & $9.16-14.2$ & $<0.001$ \\
\hline Cholesterol (mg) & $190 \pm 11.9$ & $182 \pm 11.8$ & $188 \pm 12.9$ & $148 \pm 11.1$ & $-33.4 \pm 15.1$ & $-64.1--2.70$ & 0.034 \\
\hline Total protein (E\%) & $13.5 \pm 0.21$ & $13.6 \pm 0.21$ & $13.2 \pm 0.31$ & $19.5 \pm 0.40$ & $5.94 \pm 0.45$ & $5.02-6.86$ & $<0.001$ \\
\hline
\end{tabular}

${ }^{\text {a }}$ Data is expressed as means \pm SEM.

b Mean difference in the change between the HD and WD groups ((HD intervention - HD run-in) - (WD intervention- WD run-in)) with 95\% confidence interval obtained from a one-way ANCOVA with the run-in value as covariate. HD: healthy diet; WD: Western diet.

Table 3

Markers of metabolic flexibility after the run-in period and the six-week interventions with the healthy diet or the Western diet. ${ }^{2}$

\begin{tabular}{|c|c|c|c|c|c|c|c|}
\hline & \multicolumn{2}{|l|}{$\mathrm{WD}(\mathrm{n}=21)$} & \multicolumn{2}{|l|}{$\mathrm{HD}(\mathrm{n}=19)$} & \multicolumn{3}{|c|}{ TREATMENT EFFECT $^{\mathrm{b}}$} \\
\hline & Run-in & Intervention & Run-in & Intervention & Mean differences & $95 \% \mathrm{CI}$ & p-value \\
\hline \multicolumn{8}{|l|}{ Substrate oxidation } \\
\hline$\Delta \mathrm{RQ}_{\text {Clamp }}$ & $0.10 \pm 0.01$ & $0.09 \pm 0.01$ & $0.09 \pm 0.01$ & $0.09 \pm 0.01$ & $0.01 \pm 0.02$ & $-0.03-0.04$ & 0.730 \\
\hline$\Delta \mathrm{CHO}$ oxidation ${ }_{\text {Clamp }}(\mathrm{g} / \mathrm{min})$ & $0.11 \pm 0.01$ & $0.09 \pm 0.01$ & $0.09 \pm 0.01$ & $0.09 \pm 0.02$ & $0.01 \pm 0.02$ & $-0.02-0.05$ & 0.493 \\
\hline$\Delta$ Fat oxidation Clamp $_{(\mathrm{g} / \mathrm{min})}$ & $-0.04 \pm 0.00$ & $-0.04 \pm 0.01$ & $-0.03 \pm 0.00$ & $-0.04 \pm 0.00$ & $0.00 \pm 0.01$ & $-0.01-0.01$ & 0.848 \\
\hline $\mathrm{RQ}_{\text {Clamp }}$ & $0.80 \pm 0.01$ & $0.80 \pm 0.01$ & $0.81 \pm 0.01$ & $0.79 \pm 0.01$ & $-0.01 \pm 0.01$ & $-0.04-0.02$ & 0.472 \\
\hline $\mathrm{CHO}_{\text {oxidation }}$ Clamp $(\mathrm{g} / \mathrm{min})$ & $0.11 \pm 0.01$ & $0.10 \pm 0.02$ & $0.11 \pm 0.02$ & $0.09 \pm 0.01$ & $-0.02 \pm 0.02$ & $-0.05-0.02$ & 0.311 \\
\hline Fat oxidation ${ }_{\text {Clamp }}(\mathrm{g} / \mathrm{min})$ & $0.08 \pm 0.00$ & $0.08 \pm 0.00$ & $0.07 \pm 0.00$ & $0.08 \pm 0.00$ & $0.00 \pm 0.01$ & $-0.01-0.01$ & 0.661 \\
\hline $\mathrm{FFA}_{\text {Clamp }}(\mu \mathrm{mol} / \mathrm{l})$ & $482 \pm 31.2$ & $521 \pm 41.6$ & $434 \pm 25.0$ & $487 \pm 28.7$ & $-5.63 \pm 47.2$ & $-101-89.9$ & 0.906 \\
\hline $\mathrm{RQ}_{\mathrm{MM}}$ & $0.81 \pm 0.01$ & $0.83 \pm 0.01$ & $0.84 \pm 0.01$ & $0.81 \pm 0.01$ & $-0.04 \pm 0.02$ & $-0.07-0.00$ & 0.042 \\
\hline $\mathrm{CHO}_{\text {oxidation }} \mathrm{MM}(\mathrm{g} / \mathrm{min})$ & $0.11 \pm 0.02$ & $0.13 \pm 0.02$ & $0.15 \pm 0.01$ & $0.11 \pm 0.01$ & $-0.04 \pm 0.02$ & $-0.08--0.00$ & 0.031 \\
\hline Fat oxidation ${ }_{\mathrm{MM}}(\mathrm{g} / \mathrm{min})$ & $0.07 \pm 0.00$ & $0.06 \pm 0.01$ & $0.06 \pm 0.00$ & $0.07 \pm 0.00$ & $0.01 \pm 0.01$ & $0.00-0.03$ & 0.056 \\
\hline $\mathrm{FFA}_{\mathrm{MM}}(\mu \mathrm{mol} / \mathrm{l})$ & $445 \pm 32.1$ & $421 \pm 35.3$ & $394 \pm 20.4$ & $387 \pm 37.8$ & $3.86 \pm 44.6$ & $-86.4-94.1$ & 0.931 \\
\hline Glycerol $_{\mathrm{MM}}(\mu \mathrm{mol} / \mathrm{l})$ & $118 \pm 11.7$ & $97.6 \pm 7.35$ & $96.6 \pm 7.83$ & $107 \pm 13.5$ & $23.7 \pm 14.0$ & $-4.73-52.2$ & 0.099 \\
\hline \multicolumn{8}{|c|}{ Glucose metabolism and insulin sensitivity } \\
\hline Glucose $(\mathrm{mmol} / \mathrm{l})$ & $5.53 \pm 0.11$ & $5.55 \pm 0.11$ & $5.36 \pm 0.11$ & $5.43 \pm 0.11$ & $0.04 \pm 0.06$ & $-0.08-0.16$ & 0.530 \\
\hline Insulin $(\mu \mathrm{U} / \mathrm{ml})$ & $15.1 \pm 2.37$ & $13.2 \pm 0.98$ & $10.6 \pm 0.90$ & $9.66 \pm 0.76$ & $-2.27 \pm 1.06$ & $-4.41--0.13$ & 0.038 \\
\hline HOMA-IR & $3.80 \pm 0.68$ & $3.31 \pm 0.28$ & $2.53 \pm 0.23$ & $2.34 \pm 0.20$ & $-0.59 \pm 0.29$ & $-1.18-0.001$ & 0.050 \\
\hline M-value (mg/kg/min) & $6.02 \pm 0.37$ & $6.03 \pm 0.37$ & $6.65 \pm 0.66$ & $6.34 \pm 0.56$ & $-0.11 \pm 0.45$ & $-1.01-0.79$ & 0.802 \\
\hline HbA1c (\%) & $5.54 \pm 0.07$ & $5.45 \pm 0.05$ & $5.44 \pm 0.08$ & $5.31 \pm 0.07$ & $-0.09 \pm 0.06$ & $-0.22-0.03$ & 0.124 \\
\hline Fructosamines $(\mu \mathrm{mol} / \mathrm{l})$ & $219 \pm 5.70$ & $216 \pm 6.05$ & $216 \pm 4.85$ & $218 \pm 4.32$ & $2.65 \pm 7.54$ & $-12.6-17.9$ & 0.727 \\
\hline 24-h glucose $(\mathrm{mmol} / \mathrm{l})$ & $5.85 \pm 0.17$ & $5.70 \pm 0.09$ & $5.63 \pm 0.15$ & $5.73 \pm 0.16$ & $0.13 \pm 0.19$ & $-0.25-0.51$ & 0.494 \\
\hline Time of hyperglycemia" (min) & $76.1 \pm 16.1$ & $54.2 \pm 14.2$ & $73.2 \pm 16.0$ & $49.1 \pm 10.4$ & $1.16 \pm 15.1$ & $-29.7-32.0$ & 0.939 \\
\hline CONGA-1 & $5.34 \pm 0.17$ & $5.18 \pm 0.09$ & $5.09 \pm 0.17$ & $5.36 \pm 0.14$ & $0.28 \pm 0.17$ & $-0.08-0.64$ & 0.118 \\
\hline CONGA-2 & $5.25 \pm 0.17$ & $5.07 \pm 0.09$ & $5.02 \pm 0.16$ & $5.25 \pm 0.15$ & $0.29 \pm 0.18$ & $-0.08-0.66$ & 0.115 \\
\hline CONGA-4 & $5.19 \pm 0.16$ & $5.04 \pm 0.08$ & $4.97 \pm 0.16$ & $5.15 \pm 0.16$ & $0.22 \pm 0.16$ & $-0.12-0.56$ & 0.191 \\
\hline
\end{tabular}

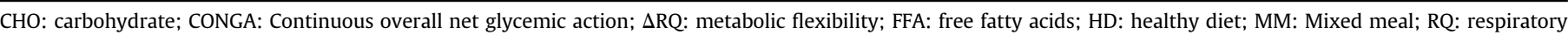
quotient; WD: Western diet.

a Data is expressed as means \pm SEM.

b Mean difference in the change between the HD and WD groups ((HD intervention - HD run-in) - (WD intervention- WD run-in)) with 95\% confidence interval obtained

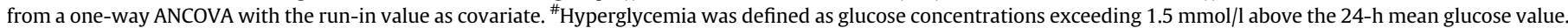

\subsection{Fasting and postprandial $R Q$ during the mixed meal challenge}

Fasting RQ measured before the mixed meal ingestion (T-30-T0) was significantly different between the two intervention groups with a more pronounced reduction in the HD group ( $p=0.042$, Table 3). In agreement, the HD reduced fasting carbohydrate oxidation when compared to the WD ( $p=0.031$, Table 3$)$. Fat oxidation in the fasting state increased with the HD, but this difference did not reach statistical significance ( $p=0.056$, Table 3 ). Although postprandial RQ was lower in the HD group throughout the mixed meal challenge, this difference was not significant when adjusting for the observed differences in fasting $R Q(p=0.610$,
Fig. 3A,B). Consistently, postprandial carbohydrate $(\mathrm{p}=0.657)$ and fat oxidation ( $p=0.468$ ) were also not significantly different between the diets (data not shown).

\subsection{Fasting and postprandial glucose and insulin during the mixed meal challenge}

When compared to the WD, changes in fasting glucose $(\mathrm{p}=0.530)$, fasting glycated hemoglobin $(\mathrm{p}=0.124)$ and fructosamines $(\mathrm{p}=0.727$ ) were not significantly affected in the HD group (Table 3). Changes in fasting insulin levels were significantly different between the groups with a smaller reduction in the HD 
A

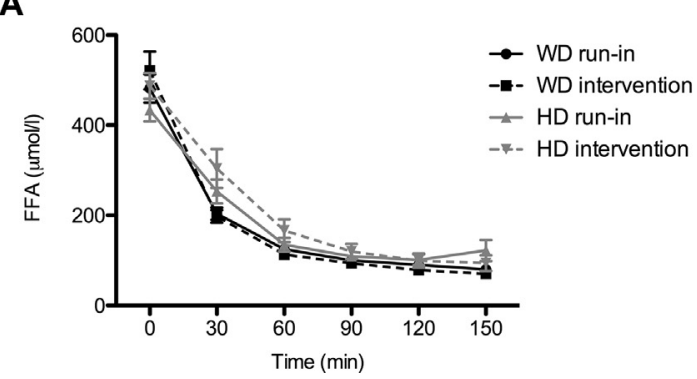

B

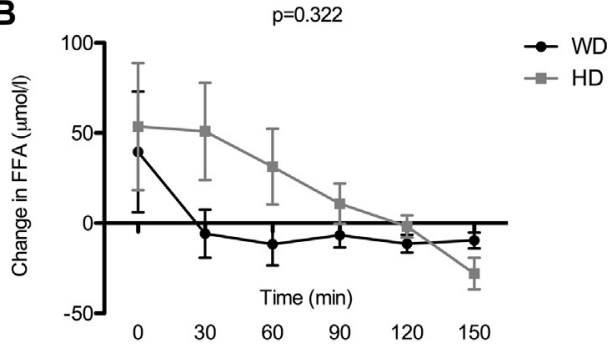

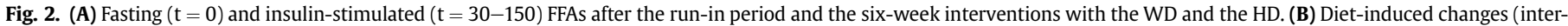

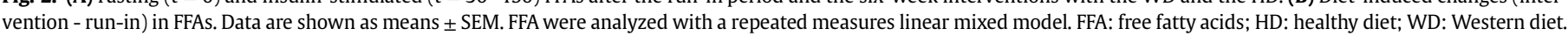

A

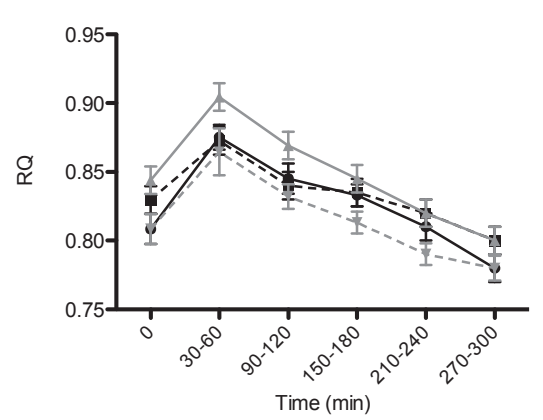

C

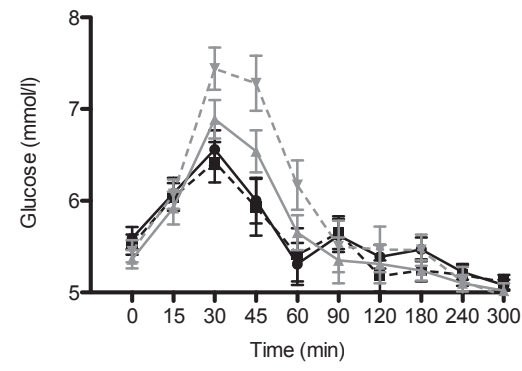

E

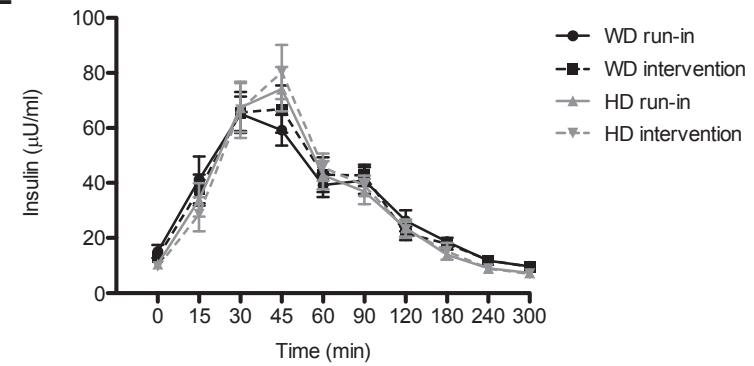

B

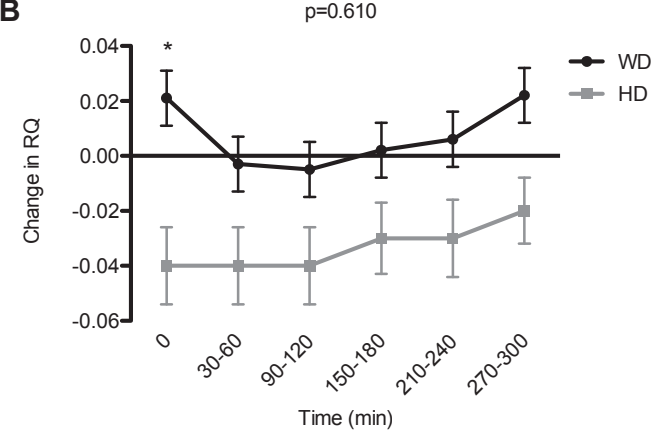

D

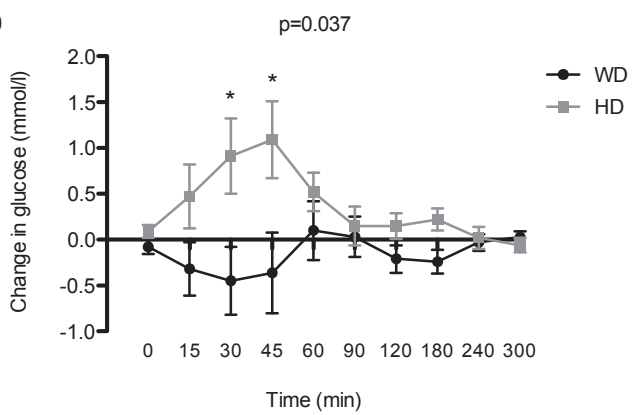

$\mathbf{F}$

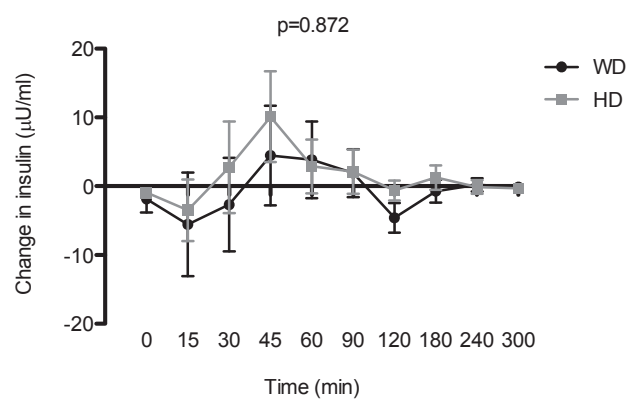

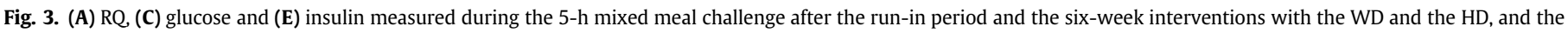

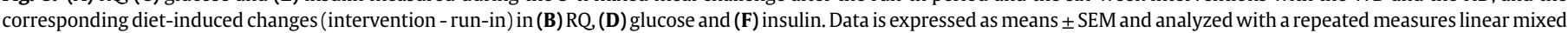
model. *Diet*time interaction is significant. The p-value shows the overall diet effect (change HD vs change WD). HD: healthy diet; RQ: respiratory quotient; WD: Western diet.

group compared to the $\mathrm{WD}(\mathrm{p}=0.038$, Table 3 ). As a result, HOMAIR was also significantly different between the groups, with a more pronounced decrease in the HD group compared to the WD $(\mathrm{p}=0.050$, Table 3$)$.
Changes in postprandial glucose profiles were significantly affected by diet $(\mathrm{p}=0.037$, Fig. 3C,D). In particular, plasma glucose levels at T30 $(\mathrm{p}=0.014)$ and $\mathrm{T} 45(\mathrm{p}=0.026)$ after meal ingestion increased more in the HD group. Changes in postprandial plasma 
insulin levels were not significantly different between the groups $(\mathrm{p}=0.872$, Fig. 3E,F).

\subsection{Mean 24-h glucose, time of hyperglycemia and glucose variability}

Average 24-h glucose levels were not significantly different between the diet groups ( $p=0.494$, Table 3$)$. Also, the time of hyperglycemia was not significantly affected by diet $(\mathrm{p}=0.939$, Table 3). Intra-day glycemic variability did not differ significantly between the diet groups when considering 1, 2 or 4 h (CONGA1, CONGA2, CONGA4, respectively, Table 3) between glucose measurements.

\subsection{Additional markers of metabolic flexibility during the mixed meal challenge}

Fasting FFA ( $\mathrm{p}=0.931)$ and glycerol $(\mathrm{p}=0.099)$ did not show a significant diet effect (Table 3 ). These markers of lipolysis both decreased upon meal ingestion, however, the change in postprandial FFA ( $p=0.314)$ and glycerol $(p=0.249)$ levels were not significantly different between the diets (data not shown). Fasting $\beta$-hydroxybutyrate $(\mathrm{p}=0.031), \alpha$-hydroxybutyrate $(\mathrm{p}=0.002)$ and isobutyrate $(p=0.007)$ were significantly different between the diet groups, with an increase in the HD compared to a decrease in the WD group (Supplementary Table 3). Also, a higher increase in acetate levels $(\mathrm{p}=0.002)$ was observed with the HD compared to the WD. The other ketone bodies acetoacetate $(p=0.059)$ and acetone $(\mathrm{p}=0.054)$ also increased more with the HD, but the diet differences were not significant. Furthermore, we observed a decrease in fasting lactate $(p=0.003)$ and pyruvate levels $(\mathrm{p}<0.001)$ with the HD compared to increases in the WD group (Supplementary Table 3). The results of all measured related metabolites, amino acids and peptides are also shown in Supplementary Table 3.

\section{Discussion}

Opposite to our hypothesis, a healthy diet for six weeks did not affect $\triangle R Q$ and insulin sensitivity as measured by the clamp. However, decreases in fasting insulin levels and HOMA-IR, and changes in fasting markers of energy metabolism were detected. Also, unexpected increases in the postprandial glucose profile were observed during a 5-h mixed meal challenge.

Metabolic inflexibility is often described as an impaired fat oxidation under fasting conditions and/or an impaired glucose oxidation in the postprandial or insulin stimulated state. Here, we assessed metabolic flexibility by measuring fuel oxidation in both metabolic states during a clamp and a mixed meal challenge. Goodpaster et al. [36] found improvements in the capacity for fat oxidation in the fasting state and for glucose utilization in the insulin-stimulated state in obese subjects after weight loss, induced by energy restriction and exercise. Solomon et al. [37] found significant improvements in metabolic flexibility and glycemic control in obese subjects, irrespective of their diet allocation to either a low-glycemic or a high-glycemic diet, both combined with a threemonths exercise program and subsequent weight loss. We here show that a six-week dietary intervention without exercise and weight loss did not affect $\Delta R Q$, suggesting that the qualitative changes in the macronutrient composition were not sufficient to improve metabolic flexibility. In a previous study, we found a decrease in metabolic flexibility after following a high fat (55 E\%) diet with a very low carbohydrate (30 $\mathrm{E} \%$ ) content compared to a low-fat (20 E\%) diet with a high carbohydrate (65 E\%) content [35]. Another study by Kahlhöfer et al. [38] showed that after a period of caloric restriction, postprandial metabolic flexibility was unaffected by refeeding with $50 \mathrm{E} \%$ carbohydrates but was clearly impaired with 65 E\% carbohydrates. These results show that metabolic flexibility can be decreased by extreme nutrient changes resulting in high fat or high carbohydrate diets. We demonstrated that the subtle replacement of $10 \mathrm{E} \%$ carbohydrates with dietary protein and replacing $7 \mathrm{E} \%$ of saturated with unsaturated fatty acids, as well as doubling the amount of fiber was not successful in improving metabolic flexibility. However, human studies using whole diet approaches to assess the impact of nutrient quality and quantity on metabolic flexibility are currently lacking.

Consistent with a lack of effect on metabolic flexibility, we did not find significant diet differences in fasting RQ before the start of the clamp. However, the fasting RQ before the mixed meal was significantly different between the diets with lower values in the HD group. Why fasting RQ changed differently in the two measurement days is not clear, as the fasting conditions of the participants before the measurements were identical. Possibly, technical limitations of gas exchange analyses may have increased measurement variability [39]. Therefore, to obtain a more complete metabolic profile, other markers of substrate oxidation were measured in the fasting state. Pyruvate and lactate levels were lower with the HD compared to the WD before the mixed meal, while levels of fasting plasma $\beta$-hydroxybutyrate, $\alpha$-hydroxybutyrate, isobutyrate and acetate were higher. As these increased plasma substrates are elevated under conditions of increased fat oxidation [40-42], these results suggest a lower glucose utilization in favor of a higher fat oxidation in the fasting state. Although we did not find improvements in $\triangle \mathrm{RQ}$, the HD might have enhanced fasting fat oxidative capacity when compared to WD.

The postprandial RQ during the mixed meal challenge was not different between HD and WD after correcting for the observed differences in fasting RQ. Interestingly, we observed a significantly higher glucose peak in the HD, as compared to the WD, 30 and 45 min after meal ingestion. These findings are contrary to our hypothesis that a healthy eating pattern would improve postprandial glucose responses. Postprandial insulin levels did not differ between the diet groups and thus cannot explain the slightly higher glucose excursion. A lower postprandial glucose oxidation in the HD group cannot explain these findings either, since no difference in oxidation was observed during the measurement between 30 and 60 min after meal ingestion. Also, a possibly altered intestinal glucose uptake is unlikely to explain the observed differences, since the postprandial glucose levels peaked at the same time in both diet groups and was not delayed with the HD. However, it should be noted that the composition of the mixed meal used for the challenge test was the same for both intervention groups and delivered a substantial amount of high-glycemic carbohydrates. Sacks et al. [43] also observed a significantly higher glucose excursion $60 \mathrm{~min}$ after an oral glucose tolerance test in overweight adults after a five-week low carbohydrate, lowglycemic index diet compared to a high carbohydrate, highglycemic index diet. It might be possible that the exposure of the HD group to a lower glycemic load for six weeks reduced their ability to cope with an acute high-glycemic load. Although our findings on the postprandial glucose profile are interesting and would suggest detrimental adaptation to a lower glycemic load, it should be noted that the differences in plasma glucose during the meal test were rather subtle, occurred within a short period of time and returned to levels comparable to the WD group $60 \mathrm{~min}$ after meal ingestion. This raises the question whether the observed adaptations are physiologically relevant or detrimental to metabolic health.

While the acute glucose profile was higher in the HD group, the 24-h glucose profile was not significantly different between the 
diet groups. During this measurement, participants were not exposed to a high-glycemic challenge. However, it remains unclear why we did not find significantly lower 24-h glucose profiles with the HD, considering the reduction in high-glycemic carbohydrates compared to the WD. It is possible that the differences between the diets in amount and type of carbohydrates may have been too small to see an effect on 24-h glucose. The lack of effect may also be explained by our healthy, normoglycemic population, or the sensitivity of the glucose sensor to pick up small differences.

Consistent with the lacking effect of the HD on $\triangle \mathrm{RQ}$, also wholebody insulin sensitivity, as measured by the clamp, was not affected by the diet intervention. However, fasting insulin levels and consequently the HOMA-IR were significantly lower with the HD compared to the WD, which may indicate an improved glucose homeostasis in the fasting state. Previous research showed that substituting dietary saturated fatty acids with polyunsaturated fatty acids [20], as well as the addition of polyphenols to a habitual diet [27] have beneficial effects on insulin sensitivity, and that legumes as part of a low-glycemic diet [44] and diets enhanced in nuts [45] or fiber [18] intake have shown to improve glycemic control, all independent of weight loss or exercise. It needs to be noted that all of these studies included insulin resistant or glucose intolerant participants, or patients with type 2 diabetes. In our study, we tested the influence of these dietary compounds in overweight or obese, but healthy participants. Their mean M-value of $6.4 \mathrm{mg} / \mathrm{kg} / \mathrm{min}$ measured before the intervention falls within the range for nonobese normal glucose-tolerant subjects [46]. The lack of improvement in whole-body insulin sensitivity, glycemic control, glucose variability and metabolic flexibility in our study might therefore be explained by the health status of our population. Additionally, we can only speculate whether effects would have become visible after an intervention period longer than six weeks.

\section{Conclusion}

A healthy diet for six weeks, without further life-style changes, did not improve metabolic flexibility, whole-body insulin sensitivity and glycemic control when compared to a Western-style diet. The surprisingly higher postprandial glucose peak in the HD group suggests a physiological adaptation to a low glycemic load diet, which only becomes visible when challenged with high glycemic foods. However, the altered postprandial glucose profile did not affect metabolic flexibility, insulin sensitivity and 24-h glucose concentrations. It remains to be determined whether the short time increase in postprandial glucose is physiologically relevant or detrimental to metabolic health.

\section{Author contributions}

LB, HPFP, DMJ, RPM and PS designed the study. EF and LB conducted the experiments and coordinated the study. CO developed the dietary guidelines and provided dietary counseling. EK performed the laboratory analyses. EF and $\mathrm{HH}$ performed the statistical analyses. EF, LB, HPFP and PS interpreted the data. EF wrote the first draft of the manuscript. LB, HPFP, RPM and PS reviewed and edited the manuscript. EF and PS had primary responsibility for the final content of the manuscript. All authors read and approved the final manuscript.

\section{Conflict of interest}

EF, LB, CO, EK, RPM and PS declare no conflict of interest. HPFP and DMJ are and $\mathrm{HH}$ was employed by Unilever, which manufactures and markets consumer food products.

\section{Financial support}

The study was funded by Unilever Food Innovation Center, Wageningen, the Netherlands.

\section{Acknowledgments}

The authors would like to thank all volunteers for participating in the study.

\section{Appendix A. Supplementary data}

Supplementary data to this article can be found online at https://doi.org/10.1016/j.clnu.2019.12.010.

\section{References}

[1] Huber MKJ, Green L, van der Horst H, Jadad AR, Kromhout D. How should we define health? BMJ 2011;343:d4163.

[2] Storlien L, Oakes ND, Kelley DE. Metabolic flexibility. Proc Nutr Soc 2004;63: $363-8$.

[3] Goodpaster BH, Sparks LM. Metabolic flexibility in health and disease. Cell Metabol 2017:25:1027-36.

[4] Galgani JE, Moro C, Ravussin E. Metabolic flexibility and insulin resistance. Am J Physiol Endocrinol Metab 2008;295:E1009-17.

[5] Kelley DE, Mandarino LJ. Hyperglycemia Normalizes insulin-stimulated skeletal-muscle glucose-oxidation and storage in noninsulin-dependent diabetesmellitus. J Clin Investig 1990;86:1999-2007.

[6] Kelley DE, Mokan M, Simoneau JA, Mandarino LJ. Interaction between glucose and free fatty-acid metabolism in human skeletal-muscle. J Clin Investig 1993:92:91-8.

[7] Zurlo F, Lillioja S, Espositodelpuente A, Nyomba BL, Raz I, Saad MF, et al. Low ratio of fat to carbohydrate oxidation as predictor of weight-gain - study of 24-H Rq. Am J Physiol 1990:259:E650-7.

[8] Kelley DE, Goodpaster B, Wing RR, Simoneau JA. Skeletal muscle fatty acid metabolism in association with insulin resistance, obesity, and weight loss. Am J Physiol Endocrinol Metab 1999;277:E1130-41.

[9] Sparks LM, Ukropcova B, Smith J, Pasarica M, Hymel D, Xie H, et al. Relation of adipose tissue to metabolic flexibility. Diabetes Res Clin Pract 2009;83:32-43.

[10] Malin SK, Haus JM, Solomon TP, Blaszczak A, Kashyap SR, Kirwan JP. Insulin sensitivity and metabolic flexibility following exercise training among different obese insulin-resistant phenotypes. Am J Physiol Endocrinol Metab 2013;305:E1292-8.

[11] Huffman KM, Redman LM, Landerman LR, Pieper CF, Stevens RD, Muehlbauer MJ, et al. Caloric restriction alters the metabolic response to a mixed-meal: results from a randomized, controlled trial. PLoS One 2012;7: e28190.

[12] Malin SK, Kullman EL, Scelsi AR, Haus JM, Filion J, Pagadala MR, et al. A wholegrain diet reduces peripheral insulin resistance and improves glucose kinetics in obese adults: a randomized-controlled trial. Metabolism 2018;82:111-7.

[13] Corpeleijn E, Saris WH, Blaak EE. Metabolic flexibility in the development of insulin resistance and type 2 diabetes: effects of lifestyle. Obes Rev 2009;10: 178-93.

[14] Kardinaal AFM, van Erk MJ, Dutman AE, Stroeve JHM, van de Steeg E, Bijlsma S, et al. Quantifying phenotypic flexibility as the response to a high-fat challenge test in different states of metabolic health. FASEB J 2015;29: 4600-13.

[15] Mursu J, Virtanen JK, Tuomainen TP, Nurmi T, Voutilainen S. Intake of fruit, berries, and vegetables and risk of type 2 diabetes in Finnish men: the kuopio ischaemic heart disease risk factor study. Am J Clin Nutr 2014;99:328-33.

[16] Mollard RC, Luhovyy BL, Panahi S, Nunez M, Hanley A, Anderson GH. Regular consumption of pulses for 8 weeks reduces metabolic syndrome risk factors in overweight and obese adults. Br J Nutr 2012;108(Suppl 1):S111-22.

[17] Jenkins DJ, Kendall CW, Augustin LS, Mitchell S, Sahye-Pudaruth S, Blanco Mejia S, et al. Effect of legumes as part of a low glycemic index diet on glycemic control and cardiovascular risk factors in type 2 diabetes mellitus: a randomized controlled trial. Arch Intern Med 2012;172:1653-60.

[18] Silva FM, Kramer CK, de Almeida JC, Steemburgo T, Gross JL, Azevedo MJ. Fiber intake and glycemic control in patients with type 2 diabetes mellitus: a systematic review with meta-analysis of randomized controlled trials. Nutr Rev 2013;71:790-801.

[19] Viguiliouk E, Kendall CW, Blanco Mejia S, Cozma AI, Ha V, Mirrahimi A, et al. Effect of tree nuts on glycemic control in diabetes: a systematic review and meta-analysis of randomized controlled dietary trials. PLoS One 2014;9: e103376.

[20] Summers LK, Fielding BA, Bradshaw HA, Ilic V, Beysen C, Clark ML, et al. Substituting dietary saturated fat with polyunsaturated fat changes abdominal fat distribution and improves insulin sensitivity. Diabetologia 2002;45: 369-77. 
[21] Mirrahimi A, Chiavaroli L, Srichaikul K, Augustin LS, Sievenpiper JL, Kendall CW, et al. The role of glycemic index and glycemic load in cardiovascular disease and its risk factors: a review of the recent literature. Curr Atheroscler Rep 2014;16:381.

[22] Li YP, Hruby A, Bernstein AM, Ley SH, Wang DD, Chiuve SE, et al. Saturated fats compared with unsaturated fats and sources of carbohydrates in relation to risk of coronary heart disease: a prospective cohort study. J Am Coll Cardiol 2015;66:1538-48.

[23] van Rossum CTM, Buurma-Rethans EJM, Vennemann FBC, Beukers M, Brants HAM, de Boer EJ, et al. The diet of the Dutch. Results of the first two years of the Dutch National Food Consumption Survey 2012-2016. National Institute for Public Health and the Environment, RIVM letter report; 2016.

[24] Harris JA, Benedict FG. A biometric study of human basal metabolism. Proc Natl Acad Sci U S A 1918;4:370-3.

[25] Human Energy Requirements. Report of a joint FAO/WHO/UNU expert consultation. Rome. 2001.

[26] DeFronzo RA, Tobin JD, Andres R. Glucose clamp technique: a method for quantifying insulin secretion and resistance. Am J Physiol 1979;237:E214-23.

[27] Paquette M, Medina Larque AS, Weisnagel SJ, Desjardins Y, Marois J, Pilon G, et al. Strawberry and cranberry polyphenols improve insulin sensitivity in insulin-resistant, non-diabetic adults: a parallel, double-blind, controlled and randomised clinical trial. Br J Nutr 2017;117:519-31.

[28] Peronnet F, Massicotte D. Table of nonprotein respiratory quotient - an update. Can J Sport Sci 1991;16:23-9.

[29] Wopereis S, Stroeve JHM, Stafleu A, Bakker GCM, Burggraaf J, van Erk MJ, et al. Multi-parameter comparison of a standardized mixed meal tolerance test in healthy and type 2 diabetic subjects: the PhenFlex challenge. Genes Nutr 2017; $12: 21$

[30] Manders RJ, Van Dijk JW, van Loon LJ. Low-intensity exercise reduces the prevalence of hyperglycemia in type 2 diabetes. Med Sci Sport Exerc 2010:42:219-25.

[31] McDonnell CM, Donath SM, Vidmar SI, Werther GA, Cameron FJ. A novel approach to continuous glucose analysis utilizing glycemic variation. Diabetes Technol Ther 2005;7:253-63.

[32] Atkin AJ, Gorely T, Clemes SA, Yates T, Edwardson C, Brage S, et al. Methods of measurement in epidemiology: sedentary behaviour. Int J Epidemiol 2012;41: $1460-71$.

[33] Westerterp KR, Wouters L, van Marken Lichtenbelt WD. The Maastricht protocol for the measurement of body composition and energy expenditure with labeled water. Obes Res 1995;3(Suppl 1):49-57.

[34] Mihaleva VV, Korhonen SP, van Duynhoven J, Niemitz M, Vervoort J, Jacobs DM. Automated quantum mechanical total line shape fitting model for quantitative NMR-based profiling of human serum metabolites. Anal Bioana Chem 2014:406:3091-102.

[35] van Herpen NA, Schrauwen-Hinderling VB, Schaart G, Mensink RP, Schrauwen P. Three weeks on a high-fat diet increases intrahepatic lipid accumulation and decreases metabolic flexibility in healthy overweight men. J Clin Endocrinol Metab 2011;96:E691-5.

[36] Goodpaster BH, Katsiaras A, Kelley DE. Enhanced fat oxidation through physical activity is associated with improvements in insulin sensitivity in obesity. Diabetes 2003:52:2191-7.

[37] Solomon TP, Haus JM, Cook MA, Flask CA, Kirwan JP. A low-glycemic diet lifestyle intervention improves fat utilization during exercise in older obese humans. Obesity 2013;21:2272-8.

[38] Kahlhofer J, Lagerpusch M, Enderle J, Eggeling B, Braun W, Pape D, et al. Carbohydrate intake and glycemic index affect substrate oxidation during a controlled weight cycle in healthy men. Eur J Clin Nutr 2014;68:1060-6.

[39] Schadewaldt P, Nowotny B, Strassburger K, Kotzka J, Roden M. Indirect calorimetry in humans: a postcalorimetric evaluation procedure for correction of metabolic monitor variability. Am J Clin Nutr 2013;97:763-73.

[40] den Besten G, van Eunen K, Groen AK, Venema K, Reijngoud DJ, Bakker BM. The role of short-chain fatty acids in the interplay between diet, gut microbiota, and host energy metabolism. J Lipid Res 2013;54:2325-40.

[41] Gall WE, Beebe K, Lawton KA, Adam KP, Mitchell MW, Nakhle PJ, et al., RISC Study Group. alpha-hydroxybutyrate is an early biomarker of insulin resistance and glucose intolerance in a nondiabetic population. PLoS One 2010;5: e10883.

[42] Puchalska P, Crawford PA. Multi-dimensional roles of ketone bodies in fuel metabolism, signaling, and therapeutics. Cell Metabol 2017;25: 262-84.

[43] Sacks FM, Carey VJ, Anderson CA, Miller 3rd ER, Copeland T, Charleston J, et al Effects of high vs low glycemic index of dietary carbohydrate on cardiovascular disease risk factors and insulin sensitivity: the OmniCarb randomized clinical trial. J Am Med Assoc 2014;312:2531-41.

[44] Ajala O, English P, Pinkney J. Systematic review and meta-analysis of different dietary approaches to the management of type 2 diabetes. Am J Clin Nutr 2013;97:505-16.

[45] Kim Y, Keogh JB, Clifton PM. Benefits of nut consumption on insulin resistance and cardiovascular risk factors: multiple potential mechanisms of actions. Nutrients 2017:9:E1271.

[46] Tam CS, Xie W, Johnson WD, Cefalu WT, Redman LM, Ravussin E. Defining insulin resistance from hyperinsulinemic-euglycemic clamps. Diabetes Care 2012:35:1605-10. 